\title{
How to Census Marine Life: ocean realm field projects
}

\author{
RON O'DOR ${ }^{1}$ and VÍCTOR ARIEL GALLARDO² \\ ${ }^{1}$ Consortium for Oceanographic Research and Education, Suite 420, 1201 New York Ave. NW, \\ Washington, DC 20005. E-mail rodor@coreocean.org \\ ${ }_{2}^{2}$ COML Scientific Steering Committee, Centro de Investigación Oceanográfica en el Pacífico Sur-Oriental, \\ Universidad de Concepción, Chile.
}

\begin{abstract}
SUMMARY: COML field projects will extend our understanding of ocean diversity, distribution and abundance from the nearshore to the abyssal plains. In nearshore, coastal and the upper ocean zones where diversity is reasonably well known it will add details about ranges, migrations and population size, but in the deep ocean there are still likely millions of new species to be described. Global coverage with standard, economical protocols is the goal in the shallow zones, but demonstrating and calibrating efficient new technologies in the deeps may be all that is possible in the 10 year life of the program. Representative sampling from such challenging habitats as the continental margins, abyssal plains, seamounts, deep sea vents, ice-covered oceans and kilometers deep mid-waters is planned. There is even a plan to reveal the four billion years of evolution in the microbial oceans, but strong global cooperation, participation and investment will be require to make the these vast hidden realms as well know as the human edges. There is great interest and international teams supporting the COML now and its legacy in Ocean Biogeographic Information System (OBIS) and Global Biodiversity Information Facility (GBIF) will be the foundation of future monitoring and assessment of ocean life.
\end{abstract}

Keywords: oceans, species, biogeography, biohistory, diversity.

RESUMEN: CÓMO CENSAR LA VIDA MARINA: PROYECTOS DE CAMPO EN EL REINO OCEÁNICO. - Los proyectos de campo del Programa Censo de la Vida Marina, aumentarán nuestra comprensión de la diversidad en el océano, su distribución y abundancia, desde el litoral hasta las planicies abisales. En las zonas costeras y en las zonas superficiales del océano, donde existe un conocimiento razonable de la diversidad, el programa agregará detalles sobre los rangos de distribución, las migraciones y los tamaños poblacionales, pero en el océano profundo probablemente existen millones de nuevas especies por describir. En las zonas someras la meta es lograr una cobertura global, aplicando protocolos estándares de bajo costo. En las profundidades, sin embargo, en los diez años que durará el programa, las metas son más modestas y se centrarán principalmente en la puesta a punto y calibración de tecnologías innovadoras. Existen planes para muestrear representativamente hábitats tan difíciles de acceso como los márgenes continentales, las planicies abisales, los montes submarinos, los océanos cubiertos de hielos y las aguas intermedias de miles de kilómetros de profundidad. El programa incluye un plan para desvelar los cuatro mil millones de años de evolución de los microorganismos que pueblan los océanos, pero se requerirá la cooperación global, la participación y la inversión de importantes recursos financieros para hacer que estos vastos dominios sean tan bien conocidos como las orillas habitadas del océano. El Programa Censo de la Vida Marina y su herencia constituida por el Ocean Biogeographic Information System (OBIS) y la Global Biodiversity Information Facility (GBIF) reciben en la acutalidad un gran interés y el apoyo de numerosos grupos internacionales de investigación.

Palabras clave: océanos, especies, biogeografía, biohistoria, diversidad.

\section{OCEAN REALM FIELD PROJECTS. WHAT LIVES IN THE OCEANS NOW?}

In each realm described in Yarincik and O'Dor (2005) and on the Census of Marine Life (COML) web portal (www.coml.org), one or more field proj- ects are developing an efficient approach to exploration. Regional and national implementation committees will broaden their coverage of realms by encouraging and promoting investment by foundations, governments and international agencies. Common approaches globally ensure that results 
exploit the opportunity to visualize global patterns and thus test global hypotheses. Each project pursues a goal that is an adaptation to its realm of the COML goal of assessment and explanation. All projects will incorporate their data in OBIS.

\section{HUMAN EDGES}

In Figure 2 of Yarincik and O’Dor (2005), pink continental shelves, only $10 \%$ of ocean area, contain most known biodiversity. Shelves, most important to and impacted by humanity, lie mostly within the exclusive economic zones (EEZs) of nations. These Human Edges are divided into nearshore and coastal zones.

\section{Nearshore}

The accessible nearshore has been studied in minute detail in many locales. The nearshore, however, stretches millions of kilometers around all oceans, across latitude, and across climates. Further, because the locales of the nearshore are linked, spawning in adjacent or even remote bays influences recruitment in other bays. Testing nearshore ecology hypotheses requires similarly linked researchers across latitude, climate, and ecosystems, the essentials of COML.

\section{Natural Geography in Shore Areas (NaGISA) goal}

From a beginning around the Pacific Rim, link researchers across latitude and climate in all oceans to assess and then visualize and explain nearshore biodiversity patterns.

By 2005 Accepted by the SSC in 2002, NaGISA is demonstrating on the Pacific Rim the power of international collaboration to sample along the elongated nearshore. From its inception, NaGISA used international workshops to create simple, efficient standards for running and recording transects from shore to 10 meters depth using SCUBA and minimally destructive manual sampling techniques focused on the benthos. These protocols are readily available on the web through the COML portal. NaGISA produces an extensive, consistent database on nearshore biodiversity to supplement and enhance intensive, idiosyncratic ones focused on local problems.

Building on site-selection criteria and sampling protocols developed during the International Biodiversity Observation Year (IBOY), NaGISA aims to achieve wide coverage with standardized techniques for future comparisons. Figure 1 shows the span of the project, 360 degrees around the equator through the Pacific, Indian and Atlantic Oceans and north-south, over 160 degrees from the Arctic Ocean to McMurdo Sound in Antarctica's Southern Ocean.

NaGISA means "coastal environment" in Japanese, and a center at Kyoto University coordinates the project. NaGISA initially focused on biodiversity gradients along the western Pacific coastline, but now it has established sampling sites in seven countries and four oceans from Alaska to Indonesia to Florida. Scientists and funding is committed to complete initial sampling in a dozen 20degree squares. Training for field sampling and sorting is underway throughout Asia, and experts for explorations are identified. The NaGISA approach has attracted scientists in more than thirty countries, who committed to using NaGISA protocols and raising local funds. South American and European

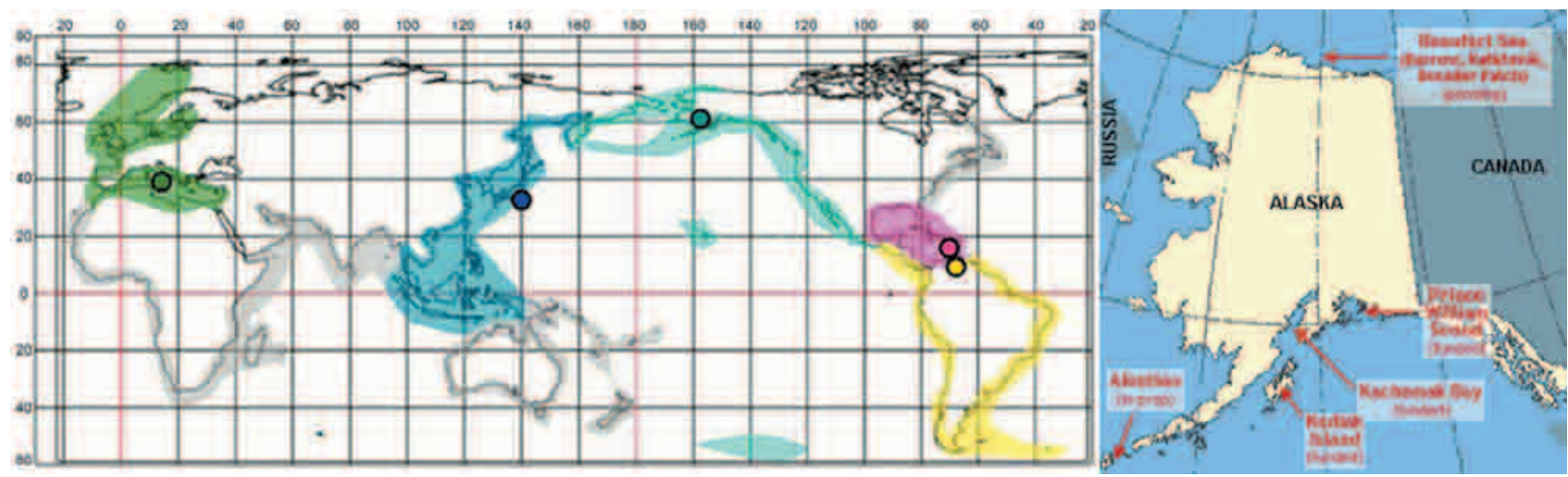

FIG. 1. - (Left) NaGISA aims to sample at least three sites from high tide to $10 \mathrm{~m}$ depth in each of these 20 -degree squares using its regional centers (dots) to build up a global map of low-tech biodiversity. Areas in grey are in planning for 2006 (right). The current sampling areas in Alaska. More sampling and more complex protocols are encouraged, but global coverage is the principal goal. (Shirayama et al., 2002) 
NaGISA initiatives are completing the Pacific circle and will eventually encircle the Atlantic.

2005-9 NaGISA will begin east-west pattern comparisons for major taxonomic groups by 2006. The Web site that provides the essential communication link amongst participants, and the NaGISA database will contribute to OBIS as samples are processed. Comparisons between basins should be possible by 2010 .

NaGISA's feasibility is proven, and it is committed to establishing at least three sites in the 130 20-degree squares on the planet that contain shoreline (Fig. 1). Its Japanese center will complete the Pacific rim first, and the European center makes it likely that the North Atlantic will be next, followed by South America, Africa, the Indian Ocean and Oceania. The methods require no sophisticated or expensive ships or equipment, allowing scientists in developing countries or supervised volunteers to run them. They can be easily incorporated into existing protocols, adding capacity for large-scale comparisons to any nearshore experiment or most effectively be incorporated into monitoring of local areas, thus allowing current project managers to benefit from international taxonomic expertise. Protocols for macrophyte and seagrass habitats will work on selected coastlines from Arctic to Antarctic to provide a baseline for testing hypotheses about latitudinal variation in marine biodiversity. Additional protocols can add rocky and sandy shores, and NaGISA will work closely with the coral reef project.

2010 NaGISA seems poised to be the first fully global marine census completed. By 2010 the samples from the Pacific Rim should be in place for testing hypotheses explaining differences in diversity from north-to-south, east-to-west and between basins. Although NaGISA emphasizes wide-scale, one-time global sampling in seasons of maximum diversity in areas of minimum human impact, it will bequeath a legacy of baselines for long-term monitoring by local and seasonal transects. Japan plans to repeat sampling every five years for 50 years, so global warming can be expected to create a natural experiment to study the impacts of temperature on large-scale biodiversity patterns along the north-south gradient.

\section{Global Census of Coral Reef Ecosystems (GCCRE) goal}

To link researchers across latitude and climate with standardized approaches for the complex habi- tats created by corals, analogous to those of NaGISA, to assess, visualize, and explain diversity patterns before they are further affected by global changes.

By 2005 In 2003, COML endorsed the development of a global Ocean Realm Project on coral reefs. At the national (Australia, USA), regional (Caribbean) and international level, leading coral reef scientists have convened to identify the major goals of a coral reef project: 1) collection and synthesis of existing taxonomic and ecological information on coral reef organisms, 2) development of new technologies, particularly DNA-based, to greatly speed up characterization and understanding of coral reef biodiversity, 3) new initiatives in the taxonomy of diverse but under-studied groups-especially sponges, octocorals, mollusks, echinoderms, decapods, polychaetes, tunicates, seaweeds-, 4) assessment of sampling devices to characterize the diversity and resilience of reefs that differ in human disturbance intensity, 5) populating OBIS with newly collected and synthesized data, 6) estimating risks to biodiversity associated with various scenarios for future reef health (Fig. 2), and 7) establishing a wellfunded global coral reef initiative to address key knowledge gaps.

2005-9 Although scientists who study coral reefs have had several opportunities to meet and agree on the goals and structure of a COML field project, major international workshops are still needed to outline specific activities and engage data holders around the world. These will take place in 2005, and the reef project will establish its organizational structure, governance, schedules for research and reporting, and obtain its initial key financial commitments.

Field expeditions in 2005-7 will tentatively sample sites in Mexico, the Philippines, Heron Island, Hawaii, Okinawa, and Puerto Rico. Collections will be made, photographed and vouchered including DNA samples for barcoding. Existing checklists and distribution data will be utilized and verified to produce a journal review of coral reef ecosystem biodiversity. Sampling devices will be deployed on degraded and healthy reefs at each of the sites to assess diversity and resilience (as measured by recruitment) and censuses for invasive species will be made. Technology development will be a major focus, using laser scanning, barcoding and other DNA-based technologies, to determine reef health, species and abundances. Finally, workshops will be held to synthesize all of the information for use in models and distribution via OBIS. 


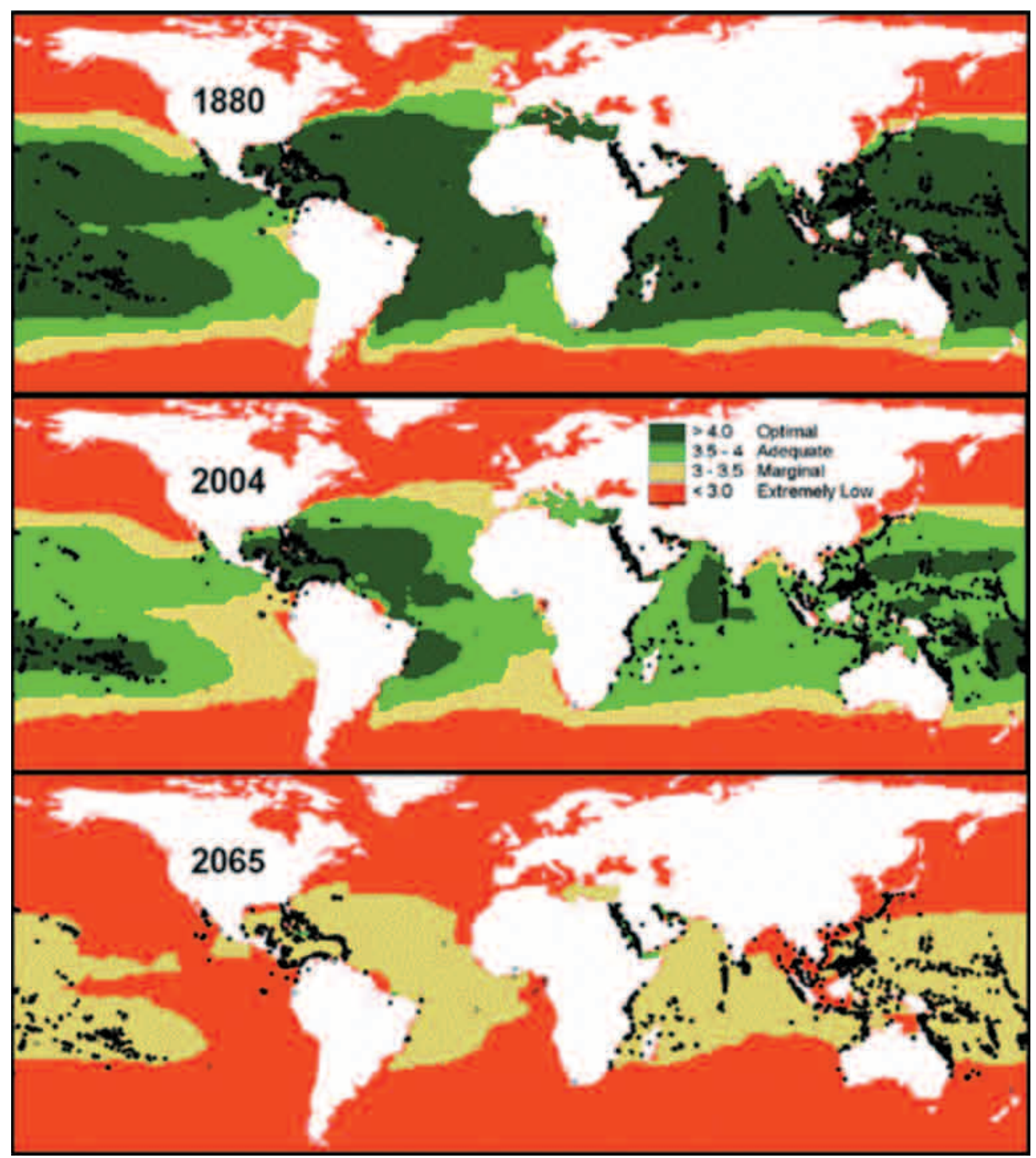

FIG. 2. - The area optimal for coral growth in terms of ocean chemistry, controlled by atmospheric carbon dioxide levels and temperature, has already dropped to a third of preindustrial levels. Most regions become marginal for coral growth in models of the future, which could be crucial to future management of biodiversity (Buddemeier, 2002).

2010 Reef biodiversity will be summarized based on globally consistent approaches in a reef ecosystem synthesis publication. OBIS will provide an ongoing framework for frequent reporting on these rapidly changing zones.

\section{Coastal}

Because $90 \%$ of the ocean harvest comes from the coastal shelves between the nearshore and the continental margins, studies have concentrated on them. For a few hundred commercial species, national agencies have long surveyed fisheries, and the FAO has collated the catch globally. Recent crises in fisheries forced a reexamination of the management of single species and evolution of new strategies for management, including transboundary species in most coastal nations. Governmental agencies recognized at an early stage the potential contributions that the Census of Marine Life could make as an independent research program. COML recognized that its program for assessing and explaining diversity, distribution, and abundanceespecially of noncommercial species-could accelerate and increase knowledge for management of commercial species at the same time it added to museum collections and subtracted from sampling cost. COML initiated two coastal Projects, one in the Gulf of Maine distinguished by assessment from seabirds above down to clams at the bottom and the other in the Northeast Pacific distinguished by tracking migrations along the shelf. 
On a coastal shelf where interests, scientists, and resources congregate, identify and collect the biological knowledge necessary for ecosystem-based management in a large marine environment. GOMA will advance knowledge of both biodiversity and ecological processes over a range of trophic levels plankton to whales and even birds - and habitats.

By 2005 In 1999, COML initiated the Gulf of Maine Area Project with a series of workshops and meetings focused on assessing biodiversity, which was surprisingly poorly known despite or because of the concentration of commercial species. In 2002, the program expanded to encompass oceanographic, physiological, ecological, and population dynamics to explain the patterns of biodiversity and predict their change. It also expanded to applying discovery to protect the Gulf ecosystem by improved management.

GOMA integrates policy and science perspectives and represents a bi-national collaboration with the Canadian Department of Fisheries and Oceans (DFO) and the U.S. National Oceanic and Atmospheric Administration (NOAA) Fisheries supporting the effort, including sharing costs and data to create the Gulf of Maine Biogeographic Information System (GMBIS). GMBIS is now online as the first regional component of OBIS, interoperable with historical data from HMAP and serving data from trawl surveys, pelagic and benthic habitat characterization and high-resolution bathymetry allowing the development of the first biophysical maps of the Gulf.
In the water column fishers contribute fish-finder records. The GOMA project and the Gulf of Maine Ocean Observation System (GOMOOS) provide continuous information about ocean physics that allows relation of biological samples both to geographic location and to concurrent observations of water temperature, salinity, currents, etc. Relating biology to water conditions is crucial because most ocean life is associated with a water mass, not a place. All GOMA sampling is being evaluated in the context of GOMOOS to ensure that the techniques standardized by the COML can contribute to OBIS' role as a key biological data framework for GOOS (Fig. 3).

Although much sampling in the Gulf can be done in association with routine fisheries surveys conducted by two cooperating national agencies, extending the study to the New England Seamount Chain added a GOMA exploration. Two NOAA Ocean Exploration cruises have done biological sampling for GOMA, while testing gear for MARECO. Published species lists from Bear Seamount include 183 species of fishes (including at least one new species), 33 species of cephalopods, and 152 other invertebrates. An interesting pattern is emerging of endemic species and long-range migrants, but many more Gulf cruises are needed to understand its true diversity.

2005-9 GOMA will develop both historical reconstruction and predictive tools through two funded projects: HMAP and FMAP in the Gulf of Maine. GMBIS will continue to integrate existing local datasets, through a new Gulf of Maine Ocean

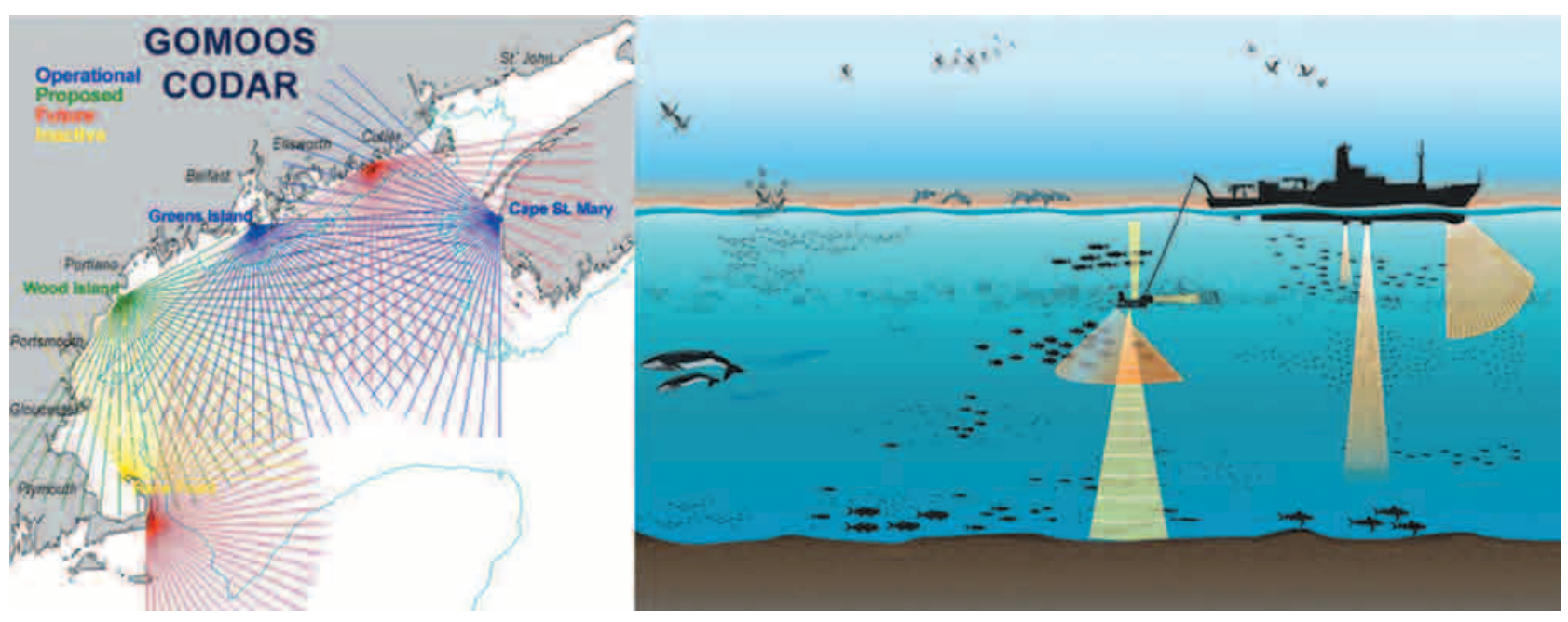

FIG. 3. - (Left) The Gulf of Maine Ocean Observation System is one of the most advance operational oceanography systems. Combined with the advanced technology from nearby research centers (Right), this makes the Gulf an ideal spot to test the limits of all aspects of the marine census approach, a test bed for linking physical and biological sampling in GOOS and for developing ecosystem management approaches. (WHOI Graphic Services and Foote, 2002) 
Data Partnership, and evolve into a dynamic digital atlas including access to remote data providers. Further field expeditions will contribute to the atlas. Observations in a "Biodiversity Corridor" along the Canada-US border stretching from the shore to the nearest seamounts will focus effort and captivate the public.

The U.S. Implementation Committee for COML has made development of integrated GOMA-like projects in the Gulfs of Mexico and Alaska a priority. In both cases ocean observation systems are developing in parallel, so this will not only build new research capacity, but also further illustrate how coastal monitoring systems can develop internationally. GOMA will serve as an example for regional ecosystem surveys.

2010 GOMA will deliver its Dynamic Atlas, plus the results of HMAP and FMAP work, and a "stateof-the-ecosystem" report for the Gulf of Maine. The legacy includes a tested model of a regional ecosystem survey. The practical consequence of the model is a sediments-to-seabirds ecosystem management plan and a cleaner, more sustainable and productive Gulf.

\section{Pacific Ocean Shelf Tracking (POST) goal}

Build a permanent acoustic tracking array for juvenile Pacific salmon and other species as small as $10 \mathrm{~g}$ along the west coast of North America as a prototype for other coasts.

By 2005 Scientists from Canada's DFO and the U.S. NOAA initiated POST, and in 2001 the SSC accepted it. Based at the Vancouver Aquarium, POST's new management board is chaired by the Canadian Commissioner to both the Pacific Salmon and North Pacific Anadromous Fish Commissions. Its membership encompasses both federal and state or provincial branches of Canadian and US governments, as well as foundations, fisheries commissions, and NGOs. POST's scientific steering group (SSG) is drawn from North American salmon experts as well as others from Australia and the North Atlantic.

The high survival observed during field studies in 2002-3 showed that the survival problem for salmon is likely not close to the river mouths and therefore calls for the deployment of a more extensive acoustic array. This demonstration of successful tagging and detection with strategically placed lines encouraged assembling a consortium of researchers from many sectors for the next phase. They envision the continental scale array of tracking stations in Figure 4. Because the West Coast shelf is often narrower than $20 \mathrm{~km}$, a string of 20-30 acoustic receivers across the shelf should detect all tagged animals crossing each line. With over $90 \%$ efficiency, these acoustic curtains have tracked and identified smolts, immature or maturing shelf-resident salmon and sturgeon stocks passing them.

A focused array was built in the large "Salish Sea" enclosed by Vancouver Island. The Salish Sea tracking demonstrated detailed measurements of residence timing, movement, and marine survival for multiple species of salmon within the Georgia Strait ecosystem and then along the open continental shelf. Within Georgia Strait, two smaller arrays in Howe Sound and Saanich Inlet tested POST's earlier findings that after leaving freshwater salmon survival is initially high. Confirming this is important because it will encourage development of the extensive array envisioned in Figure 4. With further collaborators, POST deployed an array in 2004 in south Puget Sound, which will soon be followed by the Hood Canal region and along the coastal shelf north of the Columbia River.

2005-9 Tracking of a spectrum of animals from squid to eels to whales implanted with acoustic tags is planned for 2005 in a skeleton continental-scale acoustic array from Washington to Alaska to demonstrate effective monitoring of several types of largescale migrations.

A permanent seabed node to host multiple instruments is being developed and tested to make the existing deployment strategy for the acoustic receivers less costly and laborious and more reliable. POST is collaborating with commercial manufacturers to develop these seabed receivers, which will be capable of remotely uploading the collected data using underwater acoustic modems, much the way early computers were linked acoustically through telephone lines.

During 2005-6, in co-operation with the Neptune North cabled undersea observatory, POST will build one or two lines of additional acoustic receivers using fiber optic lines across the Straits of Georgia and Juan de Fuca. This collaboration will supplement the Salish array and access a refined data management system to provide a continuous data stream. Still other collaborators plan arrays in Monterey Bay, California. In Australia a similar South West Pacific system is developing. Compatible satellite-linked acoustic receivers are also being deployed on fish aggregating devices in 


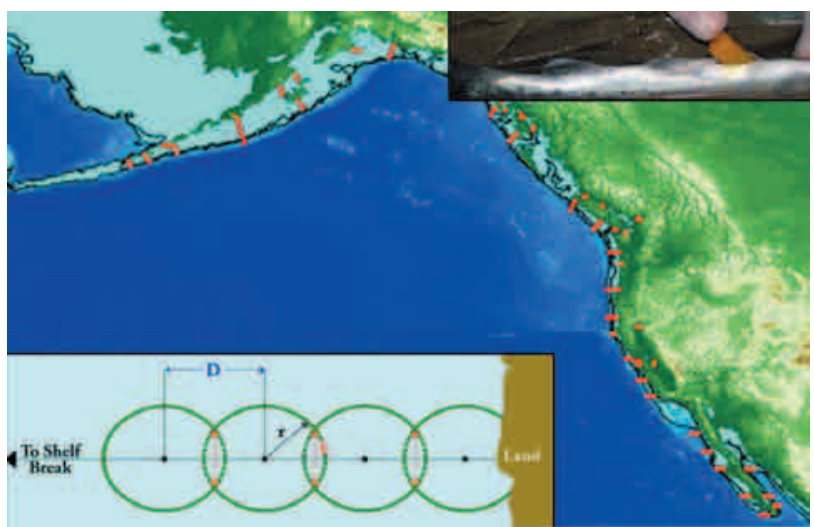

FIG. 4. - One-third of this array of "listening curtains" was in place in 2004, from the Columbia River to the Alaska panhandle. It monitored the migrations of over a thousand salmon smolts, as well as some unexpected sturgeon that had been tagged in local studies in California rivers. The insets show a schematic the overlapping radii of a line of acoustic receivers (bottom left) and the surgical implanting of an acoustic tag that can produce a quarter-million different codes and be placed in an animal as small as $10 \mathrm{~g}$ (top right). (Welch et al., 2002)

mid-ocean, so these systems may eventually be linked. Data on the migrations of a wide variety of species will eventually be compiled and made available in OBIS.

2010 POST will have tested and demonstrated continental-scale acoustic tracking by a consortium of salmon researchers, as well as applying the array to other species during their coastal migrations. It will establish the time and locations of oceanic salmon mortality and clues to its cause. It will enter the accumulated migratory tracks in OBIS and contribute to the COML dynamic atlas. POST's legacy will be an international network of listening devices stretching from the shore to the edge of the shelf and stretching along a continent, and will have stimulated similar systems on many of the other shelves. The POST arrays will be a coastal component of GOOS.

\section{HIDDEN BOUNDARIES}

\section{Continental margins}

Although their distance from shore and depth inhibited exploration of the margins until recently, we now know that the sloping margins are often unstable and changing. Improving technologies for fishing and oil exploration have pushed down the slopes to reveal challenges few imagined a decade ago. Sonar and seismic images of the lower margins reveal that apparently uniform slopes hide mixtures of rock, sand, mud, and methane hydrates. Underwater land- slides that alter local habitats and powerful currents mix water layers and scrub the bottom. These energyrich areas likely have high biodiversity, but have been poorly sampled until recently.

\section{Continental Margin Ecosystems (CoMargE) goal}

Establish biodiversity baselines in areas still untouched by commercial exploitation, collecting evidence of changes from such activities in vast areas of margins, and learning the slope's role in the evolution and distribution of species in zones above and below.

By 2005 A 'known-unknown-unknowable' workshop in August 2003 developed basic information and concepts, which contributed to the development of the Hotspot Ecosystem Research on the Margins of European Seas (HERMES), recently funded European $6^{\text {th }}$ Framework Programme. IFREMER in France, a HERMES partner, will host CoMargE with strong partnerships in other regions. There is valuable synergy between the participants and interests of CoMargE and other COML projects, including ChEss, CeDAMar and ICOMM, which will help to identify and describe the many new species to be found in this poorly studied realm. Indeed, many fundamental questions about marine biodiversity hinge on the interactions of these realms. The major interest in and access to the margins stems from oil exploration. Thus, the initial focus is on benthic diversity, but great potential for new species also exists in the highly productive near-bottom waters and the mid-waters above, as demonstrated by increasing fishing activity.

2005-9 By May 2005, the CoMargE will have established its organizational structure, governance, schedules for research and reporting, and obtained its initial key financial commitments. Figure 5 shows the planned cruise schedule for HERMES. An early Margins SSG goal will be to identify parallel opportunities in other regions to provide a comparative database. Commercial activity may return far more samples from the Margins than research cruises, so aggressive efforts will be made to assure a quick flow of such samples. OBIS will play a key role in integrating data, and regions where ChEss and CeDAMar are already active have a priority because the margins are thought to be sources of the biodiversity in these other realms.

2010 CoMargE will provide the first global biogeography of this realm, describing both the known and the unknown, which will remain large in this 


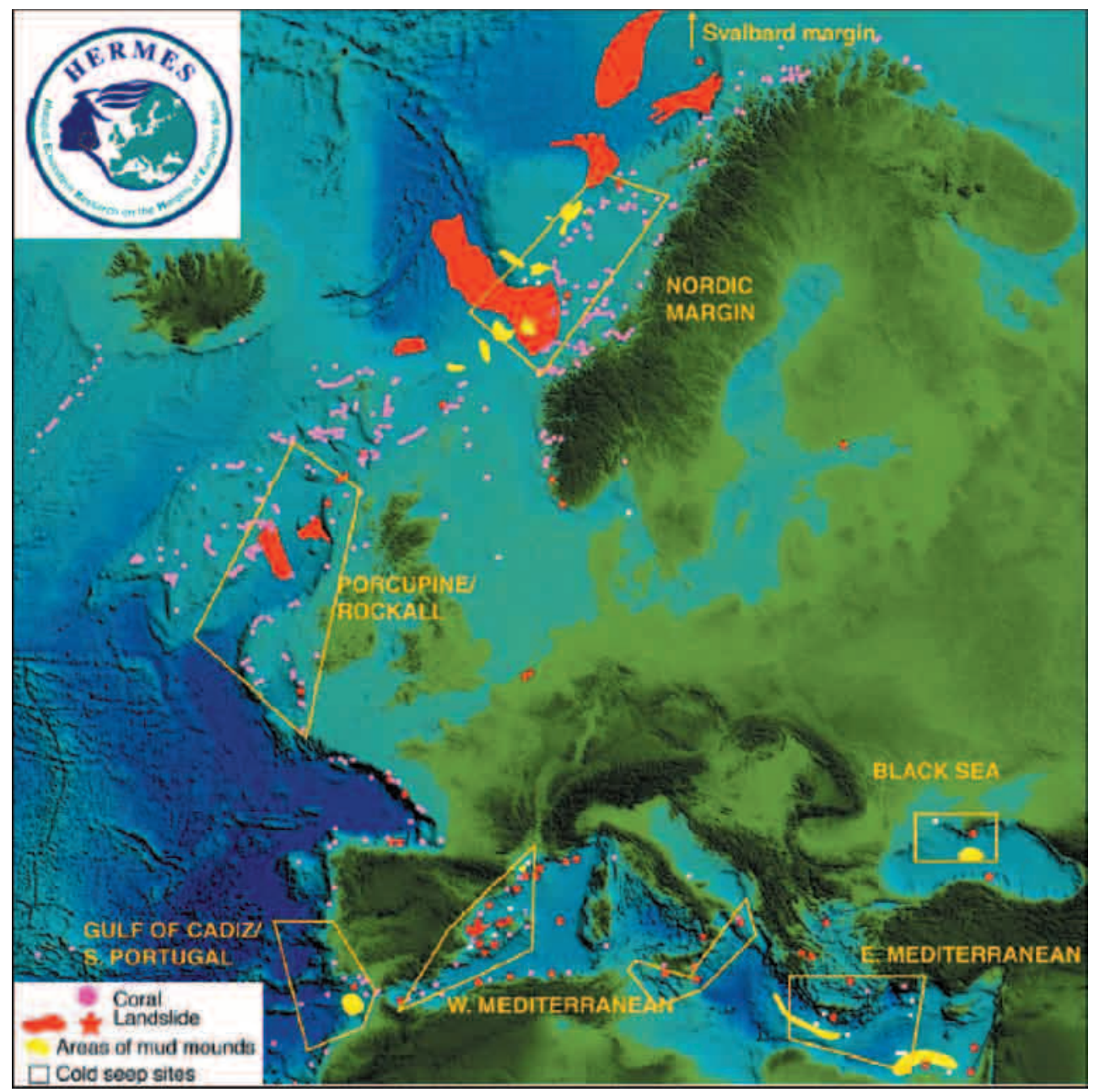

FIG. 5. - Regions for COML collaboration with the new European HERMES project will provide key initial sampling for CoMargE (modi fied from Weaver et al., 2004)

time frame. Nevertheless, there are opportunities for the OBIS database to serve as a management tool as human exploration has increasing impact on this previously dark and mysterious realm.

\section{Abyssal Plain \\ Census of Diversity of Abyssal Marine Life (CeDAMar) goal}

Describe the actual species diversity of the abyssal plains and learn what factors cause it to vary in time and space in and on the sediments.

By 2005 Coordinated from the Senckenberg Research Institute's German Centre for Marine Biodiversity Research (DZMB), CeDAMar is a dynamic part of COML contributing impressively to workshops and program development. CeDAMar has a global SSG that has successfully unified significant abyssal projects in major ocean basins. It has taxonomists for the most common abyssal fauna in two oceans and has developed a fellowship program for other taxa and other oceans. This network supports and benefits from projects like NaGISA, ChEss, ArcOD, ICOMM, and CenSeam that sample organisms in sediments.

CeDAMar has now completed two abyssal plain sampling cruises using benthic grabs and sleds in three oceans, DIVA and BIOZAIRE in the South Atlantic, ANDEEP I, II and III in the Southern Ocean and KAPLAN and NODINAUT in the North Pacific (Fig. 6). Results from these cruises were integrated at two workshops and have produced more than 70 publications. DZMB's established specimen sorting center has added hundreds of new species to its archives and will soon add them to OBIS. Five additional cruises are funded for the North Atlantic, Southern Ocean and Indian Ocean.

2005-9 Deep-sea sampling is costly. Volunteer observing ships sample millions of liters of surface 
water for plankton for not much more than the cost of netting. A couple of liters of mud from the Antarctic abyssal plain, however, can cost $\$ 100,000$ for salaries and steaming time. Thus, building a global network to exploit samples of the abyssal plain widely and in many ways is critical. The CeDAMar network is focusing on capturing and coordinating as much sampling as possible to create a global synthesis in this difficult-to-explore realm at the bottom of the ocean. To test hypotheses about such factors as productivity and latitude causing high biodiversity in the abyssal sediments, CeDAMar must first perform the challenging task of sampling the abyssal plain at several localities. This local sampling is aimed at revealing the distribution of seemingly widespread species. This knowledge of global patterns of abyssal diversity will be related to conditions in the overlying water zones. Funding in deep-sea sampling ranges from measuring carbon fluxes into sediments to geological drilling studies to nodule mining.

Crustaceans are numerous in both the abyss and the light zone, so there are synergies between the genetically-oriented CMarZ and CeDAMar. Comparisons between biodiversity encouraged by latitudinal and productivity differences in the plankton of the light zone and in the realm of the abyssal plain could give new insights into vertical transfer of energy and carbon between the water column and the bottom. Genetic comparisons between light zone and abyssal crustaceans could reveal interesting evolutionary patterns. CeDAMar will furnish samples for ICOMM.

2010 CeDAMar will make one of the largest additions to known species in the 2010 report from its unknown realm, but it certainly will not have exhausted the potential for discovery among rare species. The central unknown the abyssal will reveal is whether its common species are truly cosmopolitan and globally distributed. CeDAMar will bequeath a legacy of a global network of experts with the habit of exploiting costly abyssal samples.

\section{CENTRAL WATERS}

\section{Light Zone (drifters and swimmers)}

At least $40 \%$ of the world's primary production of biomass occurs in the open ocean, and much of this production is consumed by a community dominated by planktonic crustaceans. These organisms are relatively well studied and many are assumed to

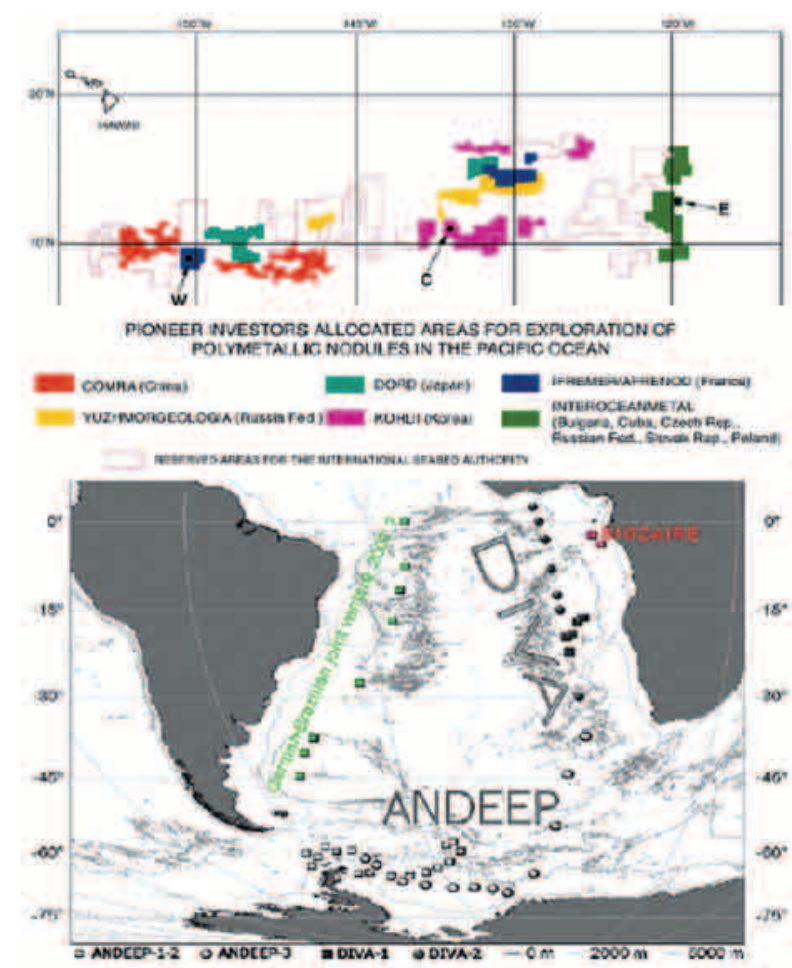

FIG. 6. - CeDAMar sites. Comparing benthic biodiversity in the Pacific (top, Adrian Glover and Craig Smith, unpublished) and Atlantic and Southern Oceans (bottom).

be cosmopolitan. The focus among the light drifters is on the question of whether this community is consistent globally, or merely convergent in a zone that requires highly constrained lifestyles. This question requires molecular tools and global assessment of populations throughout the ocean.

In contrast, there is now no question about the basinwide or even global connections among the large pelagic animals in this zone. Individual recognition, tagging and now real-time tracking of many species leaves no doubt of the scale on which these top predators must be studied. We cannot sum the whale counts in Alaska and Mexico or the tuna counts in Mexico and Japan to get a census - they are all the same individuals! New technologies are now making it possible to provide realistic estimates of the global distribution and abundance in this realm. Even animals themselves are identifying the "ocean oases" where they concentrate to feed on smaller species taking advantage of these production hotspots.

\section{Census of Marine Zooplankton (CMarZ) goal}

Global-scale analysis of all marine zooplankton groups using new and emerging technologies including molecular, optical, and acoustical imag- 


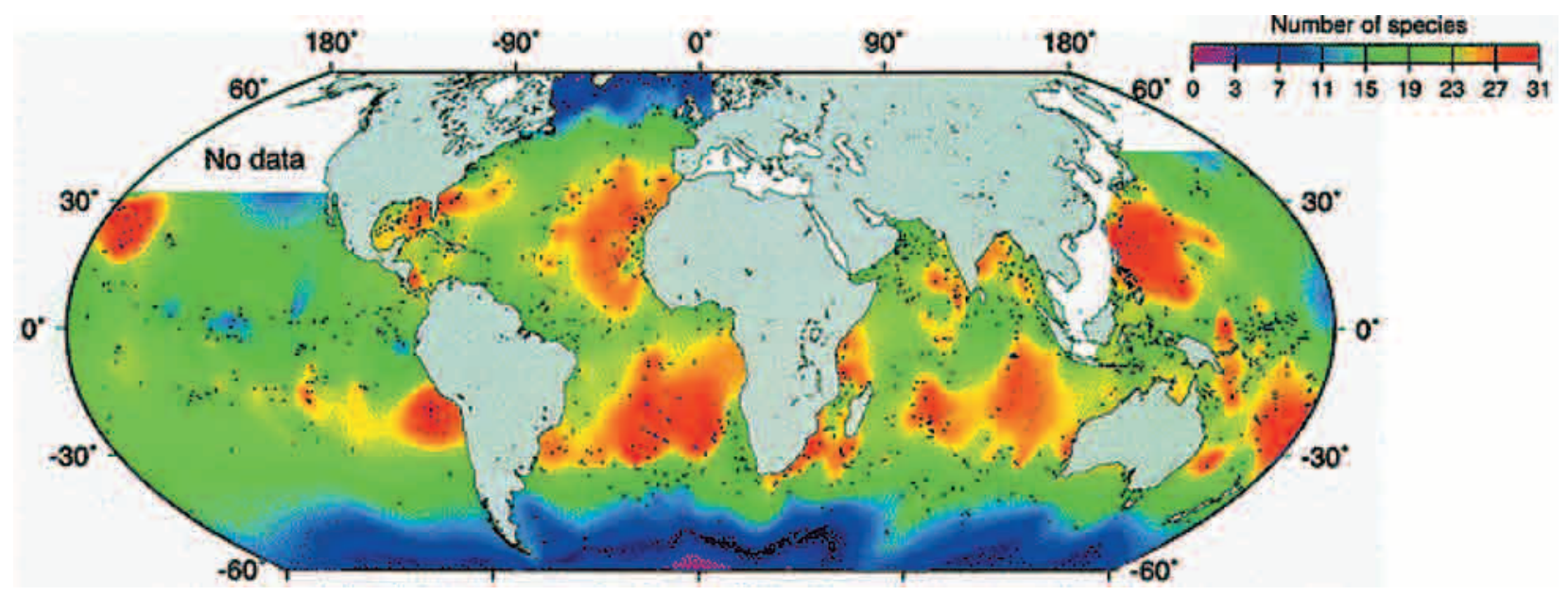

FIG. 7. - Global patterns of diversity of planktonic foraminifera (modified from Rutherford et al. 1999).

ing, and remote detection, initially focused on DNA barcoding of existing specimen collections to identify cryptic species among cosmopolitan groups.

By 2005 A 'known-unknown-unknowable' workshop in early 2004 brought together an international partnership using ships of opportunity and a coordinated international network of technicians, taxonomic experts, and biological oceanographers. The project conceived there includes centers in German, Japan and the USA and draws on a wide variety of research platforms globally, including the ships of opportunity of the Sir Alister Hardy Foundation for Ocean Science. CMarZ has nine cooperating projects - including six oceanographic cruises - launching in the first year. DNA barcoding is underway in CMarz laboratories in Japan and the USA. CMarZ is coordinating globally synoptic sampling, with strategic and statistical advice from FMAP.

2005-9 Field collections, taxonomic analysis and data analysis will be carried out by cooperating projects, ranging from annual surveys in the US EEZ by the NOAA Fisheries to three months in the Weddell Sea on the Polarstern. Training workshops will increase taxonomic capacity, ensuring accurate and consistent identification of specimens. This coordinated multinational effort seeks to complete morphological and DNA barcode analysis of at least the approximately 6,800 described species of marine metazoan and protozoan plankton by 2010. The CMarZ database will integrate with OBIS. New cooperating projects will be added as opportunities and funding arise to expand sampling to less known realms and use advanced sampling technologies (e.g., remote, autonomous, and manned submersibles). CMarZ will analyze collections from other COML projects sampling the pelagic realm.
2010 CMarZ will provide the first global synthesis of the biodiversity and biogeography of the species that make up the greatest animal biomass on the planet like that in Figure 7. It is likely to double the number of known zooplankton and will provide DNA barcodes for reliable, fast identification of zooplankton species. It will provide accurate and comprehensive assessment of relationships among light zone plankton in the world ocean, reveal new relationships to those that live in the dark zone, and inform studies of marine food webs, in which zooplankton play a pivotal role.

\section{Tagging of Pacific Pelagics (TOPP) goal}

To ally with animals as observers to create a view of vast open ocean habitats as seen by the animals themselves, especially top predators. Knowing the behavior of the top predators allows inferences about the distribution and abundance of much else that lives in the ocean, for example, where prey species accumulate. Beginning in the North Pacific, the project provides an example and advice for similar collaborations in other regions.

By 2005 Headquartered in California's Monterey Bay (Hopkins Marine Station, Monterey Bay Aquarium, and the University of California) and guided by an international SSG, TOPP scientists have tagged 19 species from albatross to albacore to elephant seals (Fig. 8). More than 40 investigators conduct projects in eight countries. By October 2004, over 1500 electronic tags of various designs were deployed, and methods developed to capture, handle, and attach a number of different tag types to pelagic allies, including Humboldt squid, a previously untagged species. 


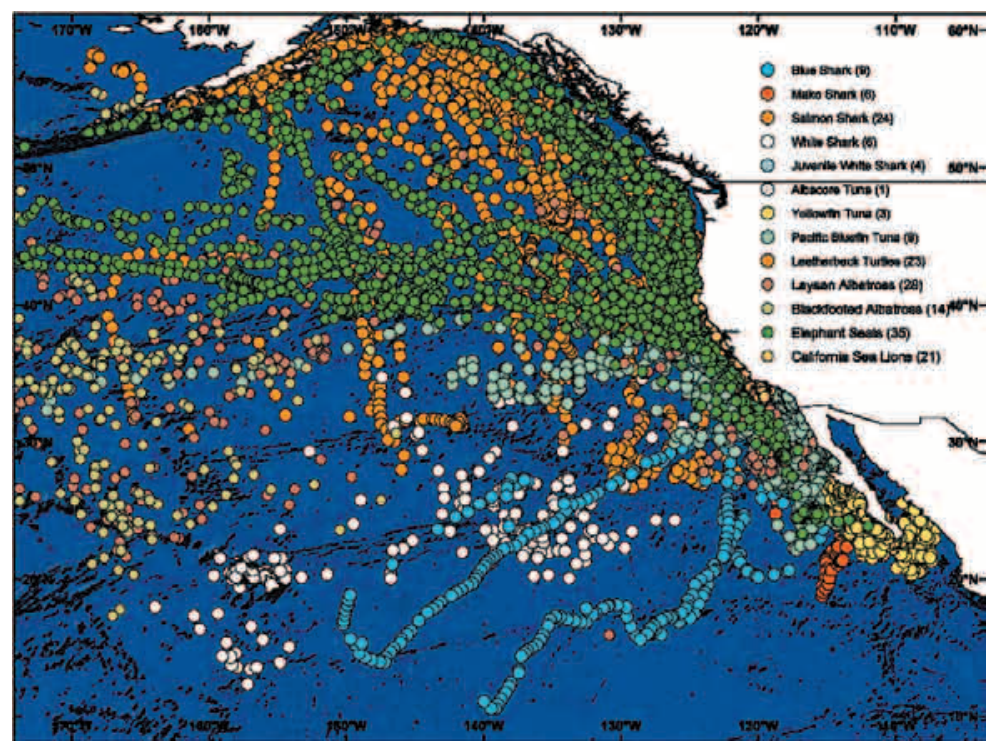

FIG. 8. - The 2002-3 tracks of nine of the 22 species tagged by TOPP to define oceanic habitat use. (Block et al., 2002) Background is spring sea surface temperature.

While performance of electronics is critical, success also requires reliable attachment of tags, and high levels of retention and recovery. Researchers working with leatherback sea turtles in Costa Rica developed attachment methods for new tags to ensure long-term retention, expanding the tagging options and providing more environmental data. Another key is to tag sufficient numbers of animals to allow statistical analysis of patterns and modeling of movements. Net pen and bait boat releases deployed 131 tagged Pacific bluefin in just four days in early 2003. Archival tags recovered yielded extensive data on tuna movements and the structure of the California Current.

Performance tests of electronic tags in the field, including double tag studies on salmon sharks, compared different geolocation methods: day length to estimate latitude and longitude against Argos satellite transmitters. A new generation of ocean sensor tags has been deployed, improving salinity, light, temperature and depth measurements. Adding TOPP animal's salinity data to North Pacific physical characteristics will improve ocean dynamic models, and everyone from students to scientists will be able to explore their journeys on an enhanced website.

2005-9 TOPP Phase II will continue with intensive deployment of tags on the 19 species already tagged and a few new ones, focused on the California Current boundary. The major challenge in this period is integrating and presenting the vast quantity of data effectively. TOPP data are not at fixed locations, are not gridded in time or location, do not have predictable delivery or location qualities and require new data management tools. A data management system is being designed to ingest data and facilitate interactive handling. Low bandwidth and intermittent connectivity must be managed and generally hidden from end users. Automated postprocessing is fundamental to correct tag data for calibration and coherency. To apply TOPP data to a wide variety of analyses, including integration with models and oceanographic data sets, its server must facilitate these analyses and provide automated notification and transmission of new data. TOPP is working closely with OBIS-SEAMAP and FMAP on these issues

This data management and server capacity will help TOPP to focus the entire global telemetry community. Many new projects adopting the TOPP model are under development beyond current efforts in the North and South Pacific. These include: 1) Novel Exploration of the Ocean (NEO), a consortium of European biologists, oceanographers, engineers, and businesses focused on bio-logging, 2) the Marine Conservation Corridor Initiative in the tropical Pacific, 3) Japan's Deep Sea Look project and 4) Southern Ocean TOPP, an idea developed at the International Bio-logging Conference in Tokyo, March 2003. Antarctic programs, already using bio-logging technology, will take advantage of TOPP's data systems to oversee national Antarctic research programs. Such data integration will facilitate management of these vast ocean areas and will be linked to the Census of Antarctic Marine Life (CAML) project.

2010 TOPP will produce a unique, integrated overview of open ocean biology in the Pacific, and 
will have aided efforts around the world. TOPP will also be an operational element of GOOS, supplementing data from autonomous underwater vehicles with focused biologically relevant data from collaborating species.

\section{Dark Zone (mid-water and bottom-water)}

\section{Patterns and Processes of Ecosystems in the Northern Mid-Atlantic (MAR-ECO) goal}

Explore and understand the distribution, abundance and trophic relationships of the organisms inhabiting the middle and deep waters of the midoceanic North Atlantic, and identify and model ecological processes that cause variability in these patterns. Focus on pelagic and benthic macrofauna, using innovative methods and up-to-date technology to map distributions, analyze community structure, study life histories, and model trophic relationships.

By 2005 A multidisciplinary transatlantic team of researchers, led by a steering group with representatives from USA, Germany, the United Kingdom, Iceland, Portugal, France and Norway, has initiated the field phase of MAR-ECO and has already carried out investigations between Iceland and the Azores using ships and submersibles. The Institute of Marine Research and the University of Bergen in Norway coordinate the efforts. The focus is the North Atlantic section of the Mid-Atlantic Ridge. Experiences here and the technological solutions found will be useful for biodiversity studies initiated by other teams on other ridges around the world.

In 2003 field sampling and observations were made from several platforms from Iceland, Russia, Germany and Portugal. The Icelandic vessel RV Arni Fridriksson conducted studies and sampling of mesopelagic fish and zooplankton in the northern end of the study area, the Reykjanes Ridge. The Russian vessel RV Smolensk and the German vessel RV Walther Herwig also conducted some sampling in the northern area. These efforts were extensions of an ICES co-ordinated survey of redfish (Sebastes sp.) in the Irminger Sea.

Perhaps the most remarkable effort was made by the Russian RV MstislavKeldysh and its manned submersibles Mir-1 and Mir-2. This was a RussiaUS collaboration, and scientists from both countries made two double dives in the Charlie-Gibbs Fracture Zone to depths of $3000-4500 \mathrm{~m}$, an area never before visited by man. Analyses of the observations and samples obtained are ongoing, and detailed results will be presented elsewhere. However, preliminary analyses of the footage from the dives document occurrence of many fish species, cephalopods, and swimming holothurians, as well as a diverse sessile macro- and megafauna dominated by suspension feeder. The density of "marine snow" and phyto-detritus on the bottom appeared higher than expected, and a particularly interesting finding was high densities of juvenile macrourid fish and holothurians.

In mid-2004, the international MAR-ECO team studied and sampled the entire study area for two months aboard the new Norwegian RV G.O. Sars (Fig. 9). This is the most comprehensive survey of this region to date, which utilized trawls and traditional sampling techniques as well as a variety of novel acoustical and optical approaches. Sampling yielded 45-50 squid species (2 potentially new to science) and 80,000 fish specimens that are still undergoing identification, although many are estimated to be new to science or new to the North Atlantic Other interesting findings included jellyfish segregating in depth layers, strange dash-line patterns of bioturbation, and amazing diversity and density of fauna associated with deep coral banks.

In the southern end of the area, MAR-ECO benefits from activities of a German-led EC funded project OASIS focusing on seamount ecosystems. Several cruises were made by Portuguese, German and UK vessels to the Sedlo seamount just south of the southern MAR-ECO Sub-area. Of particular interest were efforts to sample and study macrofauna by the Portuguese vessel RV Archipelago of the Azores also in 2004. This vessel operates longlines and provides samples for studies of trophic ecology, fish genetics, hydrography, etc.

2005-9 The field phase of the Mid-Atlantic Ridge study will continue through 2007, although the analytical phase will overlap. The MAR-ECO researchers will complete the identification of expedition collections, publish the synthesized findings and contribute data to OBIS through 2008. A wealth of information enhancing our understanding of the species, communities and ecosystems of the MidAtlantic Ridge and associated waters is expected. This will enhance the knowledgebase for advisory bodies, e.g. ICES and NAFO, and management authorities such as OSPAR, NEAFC and national governments. MAR-ECO addresses many issues listed by OSPAR as biological "uncertainties" (OSPAR, 2000). 

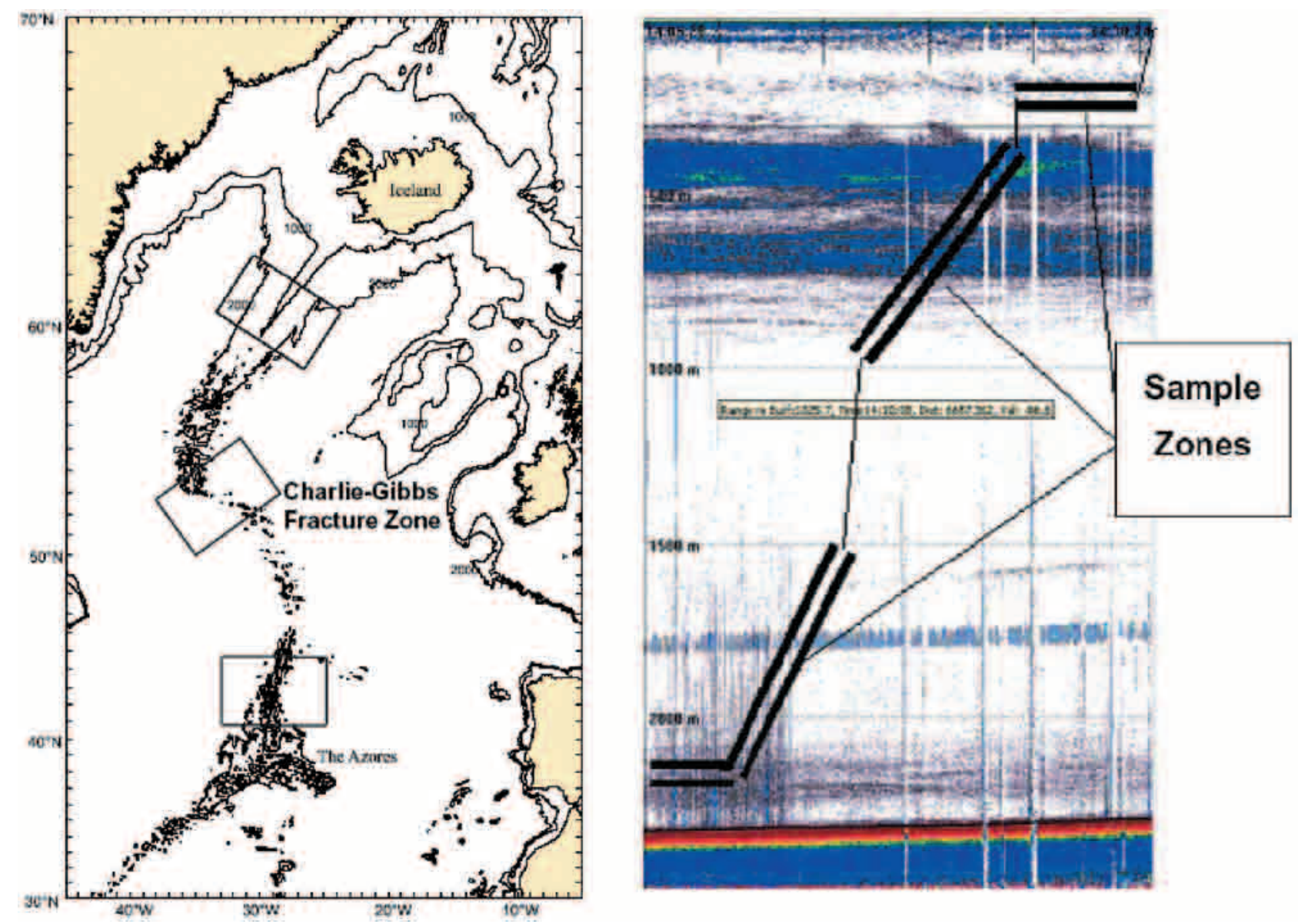

FIG. 9. - (Left) The focal areas for MAR-ECO along the Mid-Atlantic Ridge (Bergstad and Godș, 2002). (Right) A typical G.O Sars 3-km deep acoustic image of the layers of life in the water column as recorded by SIMRAD EK60, $18 \mathrm{KHz}$ echo sounder, indicating where physical samples were collected to confirm species and abundance. The vertical noise lines are typical for this frequency during steaming or bad weather.

2010 MAR-ECO will provide a comprehensive chapter on mid-oceanic species, communities and ecosystems to the final report, and its new information on known and new species will increase OBIS' third, vertical dimension (i.e. depth). It is not yet possible to predict how much of the biota of the total volume of the world's ocean will be investigated, but demonstrated success should invite imitation to gain a global view. Globalizing MAR-ECO ridge studies is a great challenge to the Census because of the vast volume involved and costly cutting-edge technology required. For this project in particular, major commitments from governments beyond the present MARECO network would be required, but the research network of the Census could make it happen.

\section{ACTIVE GEOLOGY}

As volcanic cones and eruptions plus earthquakes testify on land, seamounts, vents, and seeps testify to active geology under the ocean. Although relatively few seamounts are erupting, we group these ghost volcanoes under active geology.

\section{Biogeography of Chemosynthetic Ecosystems (ChEss) goal}

Discover new hydrothermal vents and cold seeps, assess the diversity, distribution, and abundance of their fauna in relation to other chemosynthetic ecosystems such as whale falls, sunken wood, or oxygen minimum ecosystem, perhaps remnants of Precambrian oceans, to explain the differences and similarities at the global scale.

By 2005 In January 2003 the ChEss scientific steering group convened at the Scripps Institution of Oceanography (SIO) to identify targets that would explain the biogeography of deep-water chemosynthetic ecosystems. The preliminary target areas were subsequently endorsed by the international research community and include three major priority regions 


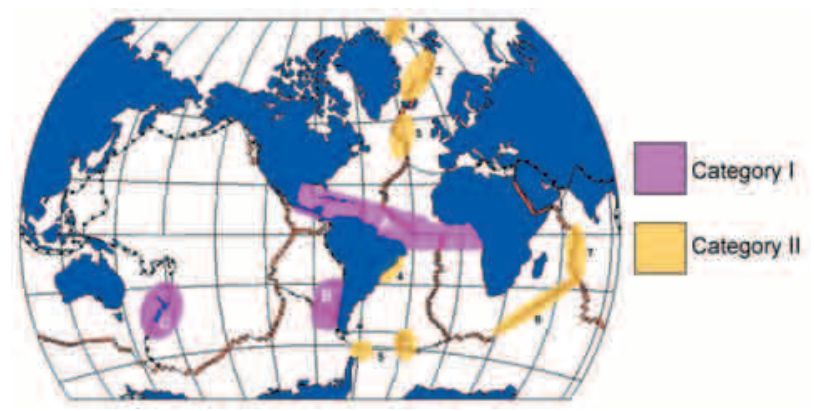

FIG. 10. - Target areas selected for ChEss where specific scientific questions relevant to biogeographical issues will be answered. Category I, combined areas for seeps, vents, and falls: Area A: Equatorial Atlantic Belt region; Area B: Southeast Pacific region; Area C: New Zealand region. Category II, specific vent areas: 1 Ice-covered Gakkel Ridge, 2 - Ultra-slow ridges of the NorwegianGreenland Sea, 3 - Northern MAR between the Iceland and Azores hot spots; 4 - Brazilian continental margin, 5 - East Scotia Ridge and Bransfield Strait, 6 - Southwest Indian FIG. 1. - Central Indian Ridge. (Tyler et al., 2002)

and a number of specific locations (Fig. 10). In parallel, ChEss developed a database on deep-water chemosynthetic species.

The major aim of the planning phase is to design and initiate the ChEss field phase. To this end, a number of additional research and education proposals are being submitted to various national, and international funding bodies to address the ChEss scope, aims, and protocols. ChEss will establish close collaboration with other ocean science programs that will for other reasons venture to sites of vents to make future research and exploration affordable. Key among these is the EuroDEEP collaborative research program for the European Science Foundation. The ChEss office is at the Southampton Oceanography Center (SOC).

2005-9 Develop the three main field programs:

-Equatorial Atlantic Belt. This area extends on a longitudinal gradient, including the following key sites: Costa Rica cold seeps, Gulf of Mexico cold seeps, Cayman Trough, Barbados Accretionary Prism, hydrothermal vents on the Mid-Atlantic Ridge north and south of the Equatorial Fracture Zones, and cold seeps on the continental margin of west Africa. The aim is to understand connectivity and isolation of geographically distant chemosynthetic ecosystems. ChEss offers to act as the umbrella program for a number of cruises funded through national programs that are already under way. Coordinated efforts amongst scientists and laboratories from the different countries involved will join efforts and ensure a maximum return from the ongoing science to benefit the community as a whole. The SOC in the UK and IFREMER in France are coordinating the umbrella project.
-Southeast Pacific region. This area encloses active vents on the Chile Rise, cold seeps on the Chile margin, a well-established OMZ on the PeruChile margin, and high potential for whale falls and sunken wood along the margin, all in close geographical proximity. The aim is to investigate the phylogenetic relationships of species where distance is not a barrier for dispersal and colonization. A Worldwide University Network international Grand Challenge program is being developed, led by SOC, SIO, and the Center for Oceanographic Research in the Eastern South Pacific (COPAS) at the University of Concepción in Chile.

-New Zealand region. This area also encompasses all chemosynthetic systems of interest to ChEss in close geographical proximity offering a good comparison site for the Southeast Pacific to investigate relationships across ocean basins. There are vents on the Kermadec arc, seeps on the east margins of the north and south island, an important whale migration route and potential for sunken wood on the southern fjords. Woods Hole Oceanographic Institution (WHOI), University of Hawaii and New Zealand's National Institute of Water and Atmosphere Researh (NIWA) coordinate this program.

2010 ChEss will have substantially increased the number of known vents and seeps. It will have discovered new species in the chemosynthetic environments and entered assessments of their new and known species diversity, distribution, and abundance into OBIS. Beyond these contributions, ChEss will bequeath its example and methods for effective international assessment and explanation of marine life in a peculiar realm.

\section{Census of Seamounts (CenSeam) goal}

To synthesize existing biodiversity knowledge and direct future field efforts towards a comparative ecology of seamounts, categorizing communities and developing proxies for generalized models. The capacity to predict properties of unexplored seamounts is an important scientific tool for urgently needed policy decisions.

By 2005 The SeamountsOnline database provides for data assembly in OBIS, and both commercial and scientific sampling on seamounts globally is rapidly expanding (Fig. 11). A global network of seamount researchers defined this project at a 'known-unknown-unknowable' workshop in August 2003. Its leaders reported outcomes to the FAO-initiated Deep Sea Conference in New 
Zealand in December 2003. Key questions identified include:

-What factors drive seamount community structure, diversity, and endemism, both at the scale of whole seamounts and individual habitats within seamounts?

-What key processes operate to cause differences between seamounts, and between seamount and non-seamount regions?

-What are the impacts of fisheries on seamount community structure and function?

A workshop with FMAP in September 2004 began defining the most efficient sampling strategies to answer these questions and targeted additional existing data resources to be brought into SeamountsOnline to guide planning for new research cruises during the field phase. The CenSeam Secretariat is hosted by NIWA in New Zealand and data management will continue through the San Diego Supercomputer Center.

In addition to updating as much species information as possible, assembling a set of physical information to provide a biologically meaningful description or categorization scheme for seamounts is important. Factors to consider include physical and geological setting (age, substrate type), geography (latitude, ocean basin, distance from nearest continental margin), size, depth, shape, and physiography, productivity of the overlying water column and its associated hydrographic characteristics (localized upwelling, presence of Taylor columns, and relationships to mesoscale oceanographic features). The work would involve an iterative process of categorizing communities, relating them to various factors, developing hypotheses about important factors/proxy variables, testing those ideas with existing or newly gathered data, and using the results to refine community categorizations. Improved fishery distribution and intensity information will also be a priority to link with the biological knowledge and provide scientific input to global concerns about the management of fisheries on seamount habitat.

2005-9 Although bringing together fragmented work on seamount ecology and biogeography is necessary, given how few seamounts have been explored, new field research will be essential. Supporting and coordinating existing efforts and developing new field projects will be priorities during this phase. Partnerships with other COML projects, particularly MAR-ECO and GOMA, and more than 20 other programs visiting seamounts in every ocean will be developed to maximize appropriate biological sampling opportunities. Details await model analysis, but there will be an active field phase because of high global interest.

2010 The roles seamounts play in the biogeography, biodiversity, productivity, and evolution of marine organisms and their effect on the global oceanic ecosystem should be clarified and quanti-

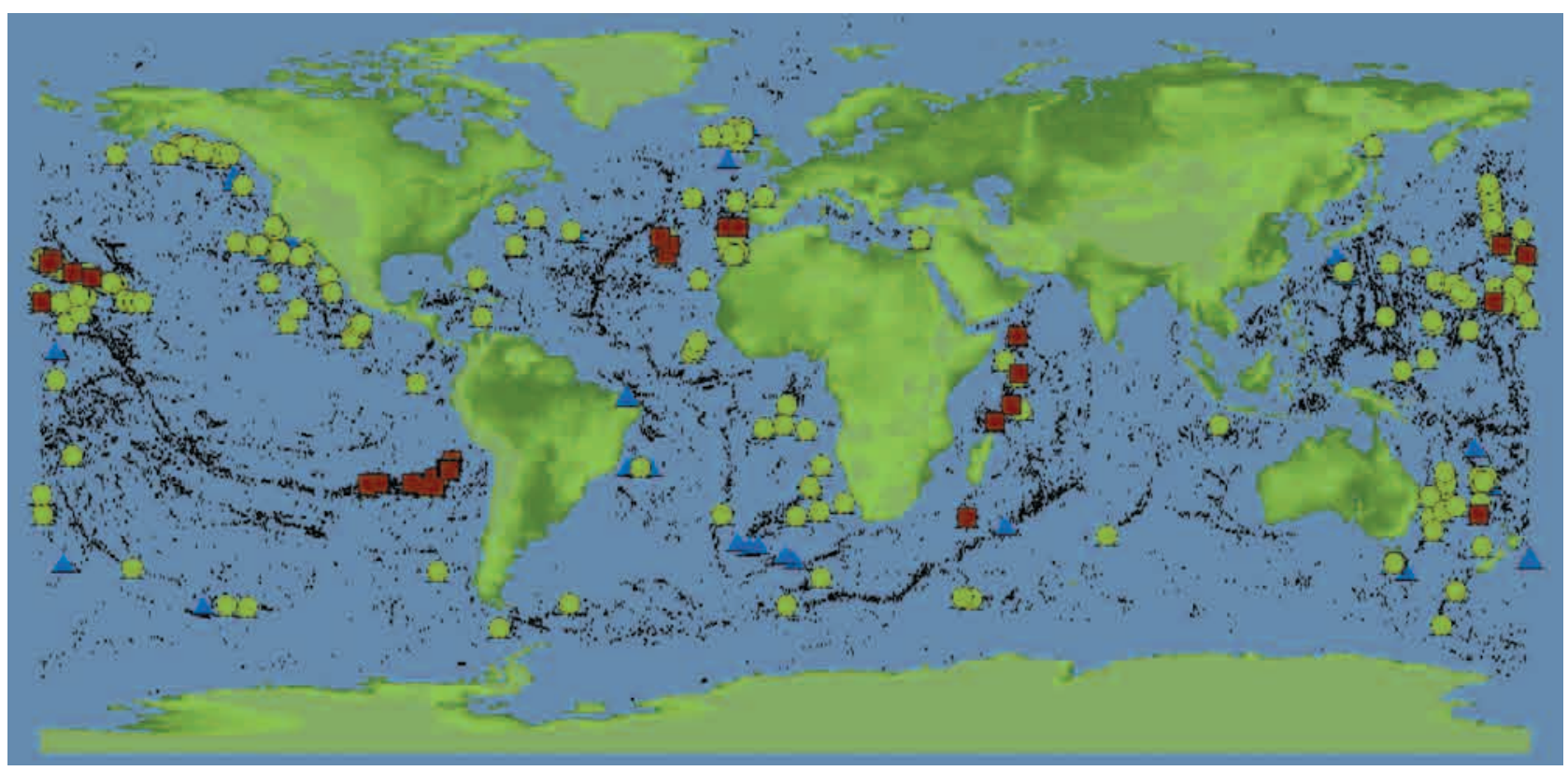

FIG. 11. - Distribution of seamounts and sampling. Small black points indicate the predicted locations of 14,300 seamounts from Kitchingman and Lai (2004). Squares indicate seamounts with data in SeamountsOnline (http://seamounts.sdsc.edu) that have received taxonomically broad sampling, circles indicate seamounts with some level of data, and triangles indicate seamounts that have been sampled biologically but for which data are not available in SeamountsOnline. 


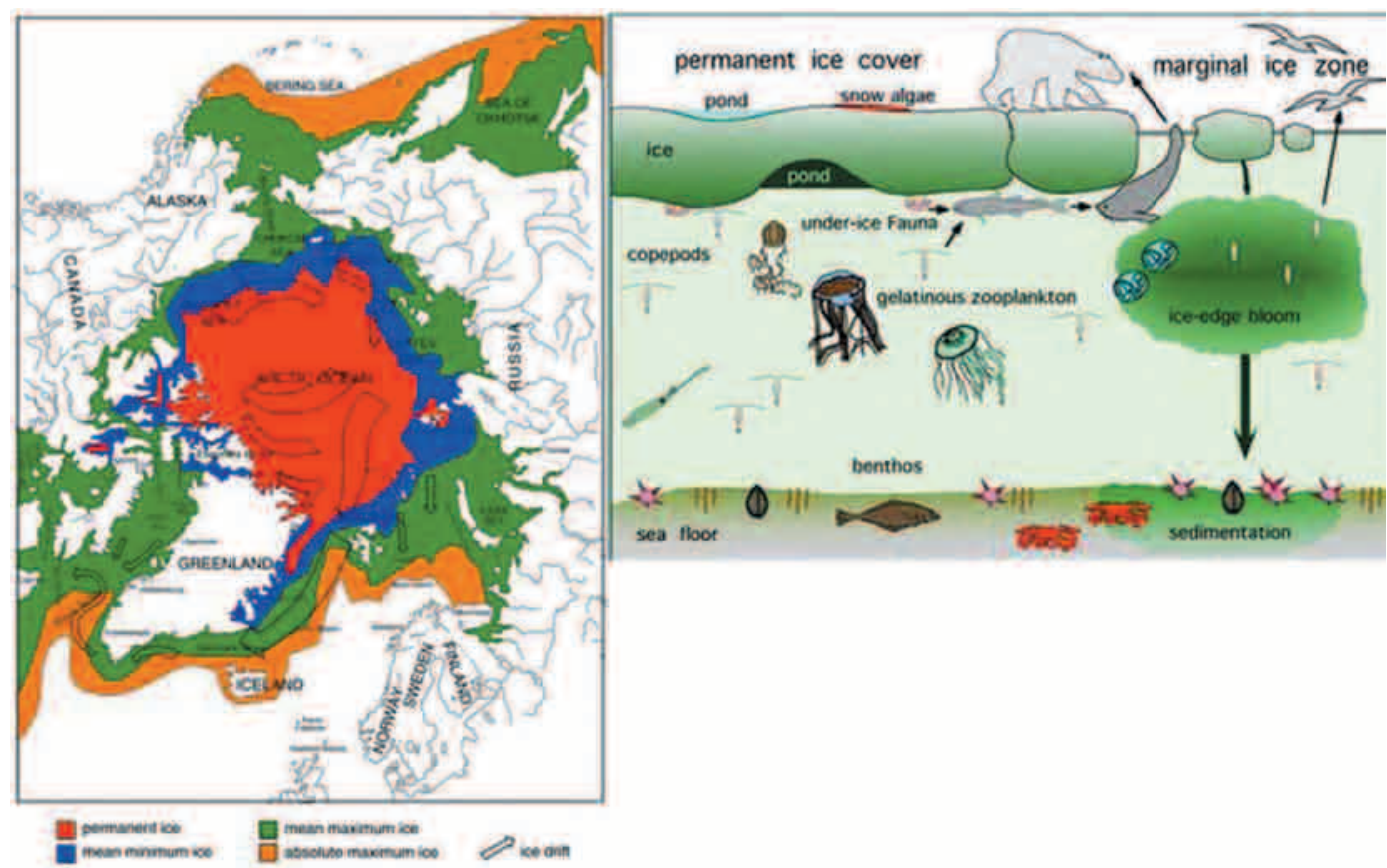

FIG. 12. - Some current models for climate change predict the complete disappearance of the permanent Arctic ice (red zone, left panel, von Quillfeldt, 1996) by 2030. ArcOD will chart the biodiversity of the currently ice-covered ecosystems, to better understand and predict the consequence of these changes on species and humans living there.

fied. The question whether seamount communities differ in ecological structure and function should be answered as well as whether seamounts act as centers of speciation, as refugia for relict populations, and/or to what extent they serve as stepping-stones for trans-oceanic dispersal. This will be a key chapter in the Census and a contribution to global efforts to manage marine resources.

\section{ICE OCEANS - ARCTIC AND ANTARCTIC}

At the ocean surface, seawater solidifies between -1.5 and $-2.0^{\circ} \mathrm{C}$ creating new transient solid habitats at each pole. Climate change appears to be raising temperatures globally and altering the sites and nature of polar life for marine species and humans. Historically such changes seem to occur faster than the movements of continents, so they provide interesting case studies in evolution, and the two poles provide an interesting contrast. Research in these regions requires special techniques and icebreaking vessels, so cruises must be carefully coordinated to sample all habitats and all scales of life.

\section{Arctic Ocean Diversity (ArcOD) goal}

Assemble existing knowledge of biodiversity in the least known ocean, direct new international explorations using new technology, and create a framework for understanding and predicting biological correlates with expected climatic changes in this rapidly changing ocean.

By 2005 The Arctic is the most extreme ocean in seasonality of light and in its year-round ice cover. It is also the ocean where climate change may be most strongly expressed. The tremendous ongoing changes make the effort to identify the diversity of life in the realms of sea ice, water column, and sea floor urgent. An Arctic Biodiversity 'known-unknown-unknowable' workshop in April 2003 defined the problems and gaps, linking scientists from countries with essential icebreaker capacity. A SCOR symposium in Moscow in September 2003 also focused on potential Russian contributions to an Arctic census and led to a Russian workshop in 2004. Current knowledge indicates that the Arctic seas hold a multitude of unique life forms adapted to the extremes. ArcOD will document the present Arctic biodiversity from an international Pan-Arctic view with an office at the University of Alaska Fairbanks and taxonomic centers in St. Petersburg and Moscow. The SSG will identify available data for entry into OBIS. Because of unique vessel requirements, the SSG is carefully cross-linked to other projects and has a strong focus on identifying cruises and International Polar Year (IPY) planning. The 
RUSALCA cruise to the Chukchi Sea in August 2004 explored the unknown Herald Canyon, reviving Russia-US collaboration.

2005-9 The core phase will compile existing data and make full taxonomic use of collected but unprocessed samples. Geographic, taxonomic and temporal gaps will be filled through new collections emphasizing active participation in the IPY activities. These will be coordinated with CAML. Russian partners will create a geo-referenced list of species of Arctic marine free-living invertebrates, record Russian expeditions and stations taken in the Arctic from 1800, and catalog some 500 Russian publications on marine Arctic fauna.

2010 The synthesis phase will integrate newly accumulated data fully into OBIS to be synthesized, published and presented at international meetings and used within HMAP and FMAP, as well as providing the Census "chapter" on the biogeography of the Arctic.

\section{Census of Antarctic Marine Life (CAML) goal}

To assemble the rich biological data on the Southern Ocean currently distributed widely internationally, to encourage biodiversity sampling on all cruises in the region, particularly during the focal period of the International Polar Year, 2007-8, and to couple this new understanding of biology to the complex current dynamics there that control gene flow through all the world's oceans.

By 2005 CAML, led by the Australian Antarctic Division, with a SCAR-appointed SSG representing seven major nations with research interests in the region, was endorsed by the Life Science Scientific Standing Group of SCAR. SCAR also supports the Marine Biodiversity Information Network (MarBIN) to consolidate data from the region in a database compatible with OBIS and GBIF. Increased commitment of existing data from a workshop in Curitiba, Brazil, in July 2005, linking MarBIN with the South American OBIS Node, will encourage South American countries to participate in IPY projects in benthic biology. Fourteen nations have already indicated an interest in providing ship time in Antarctic waters during IPY for biodiversity sampling. SCAR and SCOR are working together to coordinate cruise activity to provide interdisciplinary sampling opportunities as well as maximum coverage during IPY. The region's complex oceanography (Fig. 13) gives it a special role in distributing biodiversity.

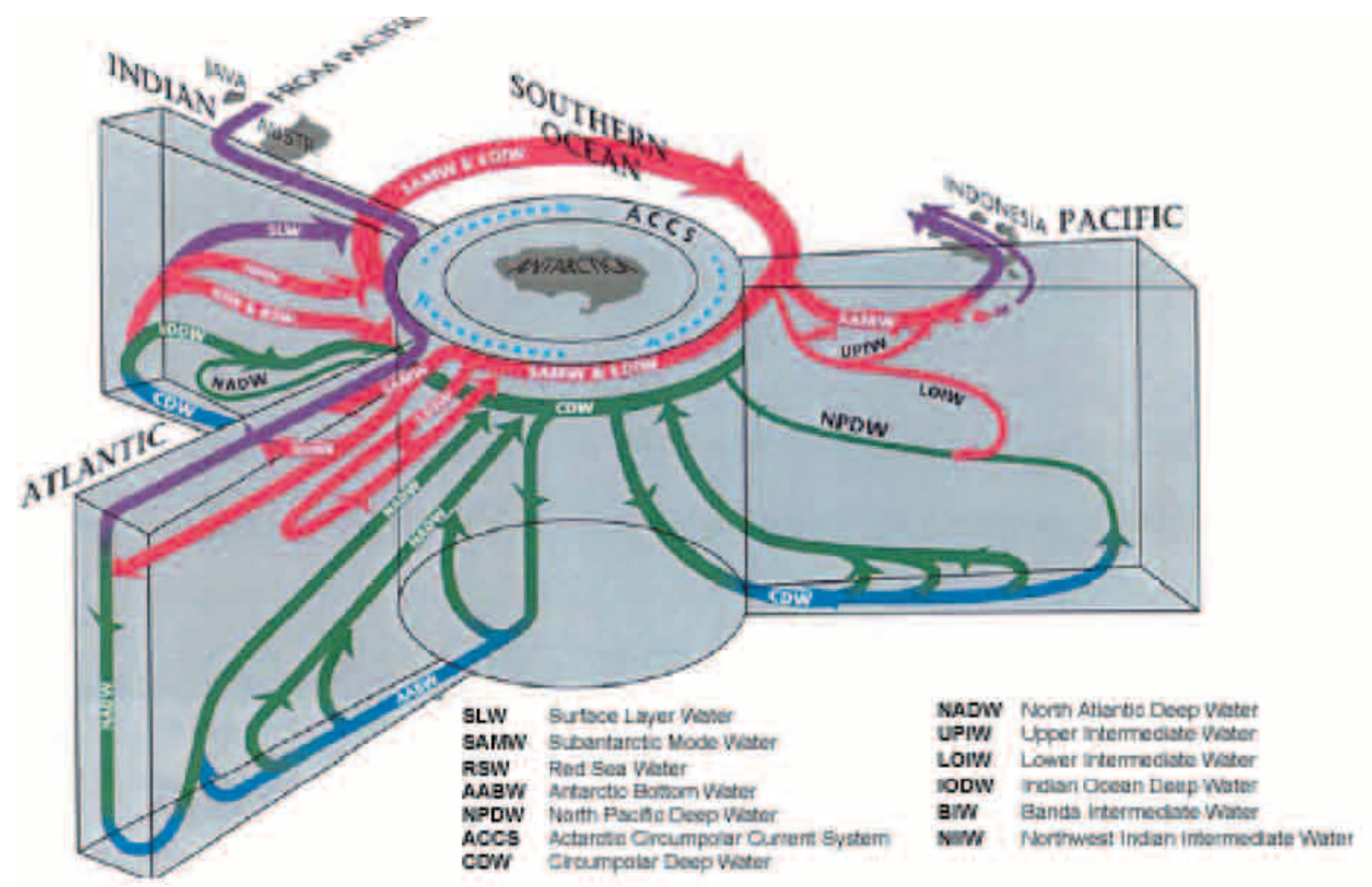

FIG. 13. - This three-dimensional representation of flows among ocean basins shows how central the Antarctic Circumpolar Current System (ACCS) is and has been to movements of marine species around the planet, in contrast to the isolated Arctic (modified from Schmitz, 1995) 


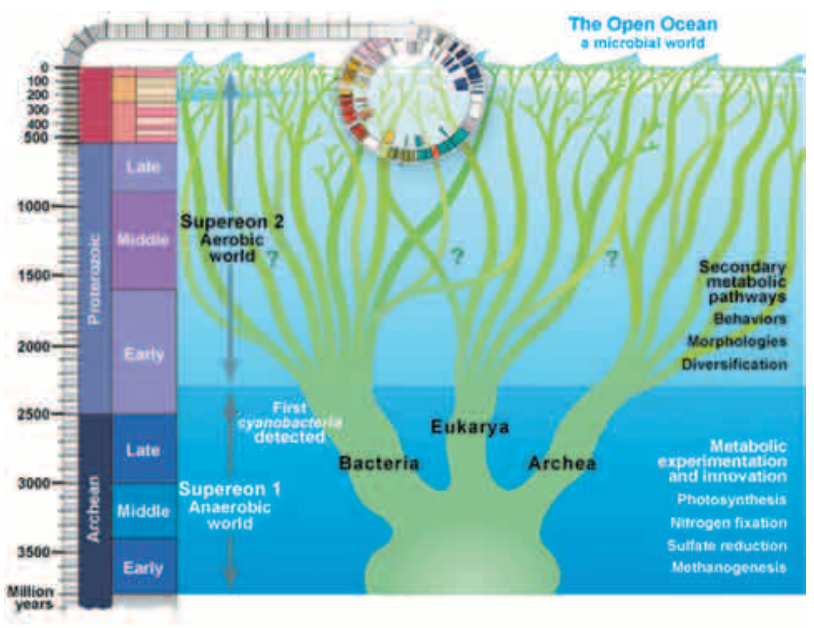

FIG. 14. - Oceans apart. Automated DNA sequencing provides a new way of exploring the record of life all the way back to its origins in the sea 4 billion years ago. Unlike barcoding, which looks at partial sequences from larger genomes in plants and animals, entire microbial genomes can be reconstructed (modified from Falkowski and de Vargas, 2004).

2005-9 Information assembly in MarBIN will make it possible to identify key areas for new exploratory sampling as well as areas where biological coverage is good, but some crucial details are lacking. Because the major field activities of CAML will take place during the IPY in 2007-2009, one of the complications of IPY is that key platforms such as icebreaking vessels will be required at both poles. COML will organize meetings between its two polar projects to ensure comparability between data sets and optimized use of people and equipment.

A major SCAR goal in IPY will be high-resolution benthic mapping, a tremendous asset for the benthic biology community and future ocean conservation. Combining these physical maps with comprehensive biological data will support application of benthic surveys developed in GOMA.

2010 Given the scheduling for IPY it will be difficult to provide a fully developed biodiversity atlas for the Antarctic by 2010, but advanced data management techniques, including integration of MarBIN with OBIS, should make it possible.

\section{THE MICROSCOPIC}

\section{International Census of Marine Microbes (ICOMM) goal}

To develop a highly resolved biodiversity database for marine microbes and to understand how microbial populations evolve, interact, and redistrib- ute on a global scale. The definitions of biodiversity among microbes will be based largely on the application of molecular techniques.

By 2005 Early in the year, the SSG for ICOMM met in Amsterdam with ICOMM organizers and chairs of working groups to review documents generated by the groups and to develop a plan for a broader community meeting. This plan must include discussion of opportunities to acquire samples and to link the information in a specially designed microbial genetic database (MICROBIS) to other web portals. MICROBIS will be subject to critical review by working groups, SSG, OBIS, and collaborators. Later in this year a meeting will be hosted for representatives of the marine microbial community to address funding and identify sampling opportunities within and outside the existing COML projects, describe common technology issues, database content including community input, and confirm potential pilot projects that could shape future funding initiatives. Examples of questions that ICOMM will address include: (1) What governs the evolution of marine microbial lineages within complex marine communities? (2) Why do marine microbial consortia retain functionally equivalent but genetically distinct lineages? (3) Is there a marine microbial biogeography and if so, what are the principal drivers or restrictors? (4) How does genotypic diversity shape phenotypic diversity, and how does this diversity influence the functioning of marine ecosystems?

2005-9 Education and outreach resources will be developed. Pilot projects will be initiated and completed by 2006. In 2006, progress will be reviewed by the working groups, ICOMM organizers and SSG will review progress and synthesize a final strategy document addressing funding opportunities, technical issues relating to sampling, sample processing, MICROBIS standards, scientific priorities, and long-term funding opportunities. These will determine the scale of the DNA sequencing approach possible and the number of samples from other COML project collections that can be processed and integrated into analyses.

2010 The "chapter" on the biogeography of marine microbes will potentially redefine our understanding of biodiversity at this level. The project explores both new regions and new concepts. The image-rich MICROBIS will provide a unique resource with cross-compatibility between biogeographic databases like OBIS and GBIF and genetic databases like GenBank. 


\section{ACKNOWLEDGEMENTS}

Odd Aksel Bergstad, Bodil Bluhm, Ann Bucklin, Richard Chinman, Malcolm Clark, Lew Incze, Donald Kohrs Nancy Knowlton, Dale Langford, Pedro Martínez, Eva Ramírez, Robin Rigby, Myriam Sibuet, Mitch Sogin, Michael Stoddart, Karen Stocks, Paul E Waggoner, Kristen Yarincik

\section{REFERENCES}

Bergstad, O.A. and O.R. Godș. - 2002. The pilot project "Patterns and processes of the ecosystems of the northern Mid-Atlantic": aims, strategy and status. Ocean. Acta, 25: 219-226.

Block, B.A., D.P. Costa, G.W. Boehlert, R.E. Kochevar. - 2002. Revealing pelagic habitat use: the tagging of Pacific pelagics program. Ocean. Acta, 25: 255-266.

Buddemeier, R.W. - 2002. http://www.kgs.ku.edu/Hexacoral/ Products/products.htm\#present

Falkowski, P.G. and C. de Vargas. - 2004. Shotgun sequencing in the sea: A blast from the past? Science, 304: 58-60.

Foote, K.G. - 2002. Pilot Census of marine life in the Gulf of Maine: contributions of technology Ocean. Acta, 25: 213-218.

Glover, A.G. and C.R. Smith. - 2003. The deep seafloor ecosystem: current status and prospects for change by 2025. Environ. Conserv., 30: 219-241.

Kitchingman, A. and S. Lau. - 2004. Inferences on potential seamount locations from mid-resolution bathymetric data. P In: Morato, T. and D. Pauly (eds). Seamounts: biodiversity and fisheries. Fisheries Centre (UBC) Research Report, 12(5): 7?12.

OSPAR. - 2000. Quality Status Report 2000, Region V - Wider Atlantic, OSPAR Commission, London, $110 \mathrm{pp}$

Rutherford, S., S.D. D'Hondt and W. Prell. - 1999. Environmental controls on the geographic distribution of zooplankton diversity. Nature, 400: 749-753.

Schmitz, W.J. - 1995. On the interbasin-scale thermohaline circulation. Rev. Geophys., 33: 151-173.

Shirayama, Y. A. Rowden, D. Gordon and H. Kawai. - 2002. Latitudinal Biodiversity in Coastal Macrophyte Communities. In: T. Nakashizuka and N. Stork, (eds), Biodiversity Research Methods IBOY in Western Pacific and Asia, pp. 162-182. Kyoto University Press and Trans Pacific Press.

Tyler, P.A., C.R. German, E. Ramirez-Llodra, C.L. Van Dover. 2002. Understanding the biogeography of chemosynthetic ecosystems. Ocean. Acta, 25: 227-241.

von Quillfeldt, C.H. - 1996. Ice algae and phytoplankton in north Norwegian and Arctic waters: species composition, succession and distribution. Ph.D. thesis, University of Tromss, 259 pp.

Weaver, P.P.E., D.S.M. Billett, A. Boetius, R. Danavaro, A. Freiwald and M. Sibuet. - 2004. Hotspot ecosystem research on Europe's deep-ocean margins. Oceanography, 17(4): 132-143.

Welch, D.W., G.W. Boehlert, B.R. Ward. - 2002. POST-the Pacific Ocean salmon tracking project. Ocean. Acta, 25: 243-254.

Yarincik, K. and R. O'Dor. - 2005. The Census of Marine Life: goals, scope and strategy. Sci. Mar., 69(Suppl. 1): 201-208. 
